\title{
CD70-Driven Chronic Immune Activation Is Protective against Atherosclerosis
}

\author{
Ronald W. van Olffen ${ }^{a}$ Alex M. de Bruin ${ }^{a}$ Mariska Vos $^{b}$ Anna D. Staniszewska ${ }^{a}$ \\ Jörg Hamann ${ }^{a}$ René A.W. van Lier ${ }^{a}$ Carlie J.M. de Vries ${ }^{b}$ Martijn A. Nolte ${ }^{a}$ \\ Departments of a Experimental Immunology and ${ }^{b}$ Medical Biochemistry, Academic Medical Center, \\ University of Amsterdam, Amsterdam, The Netherlands
}

\section{Key Words}

Atherosclerosis $\cdot \mathrm{CD} 27 \cdot \mathrm{CD} 70 \cdot$ Mice $\cdot$ Monocyte

\begin{abstract}
Chronic infection and inflammation are strongly associated with the development of atherosclerosis. To investigate whether chronic inflammation in the absence of an infectious cause also predisposes to the development of atherosclerosis, we used a mouse model in which sterile inflammation is driven by enhanced costimulation. Constitutive triggering of CD27 on T cells through overexpression of CD70 on $B$ cells increases the numbers of IFN $\gamma$-producing effector $T$ cells, which reduces the numbers of B cells. However, despite these pro-atherogenic features, we found that CD70-transgenic (CD70TG) mice on an ApoE*3-Leiden background were strongly protected against the induction of atherosclerotic lesions, with a normal increase in serum cholesterol level and the absence of atheroprotective antibodies. We found that circulating monocytes in CD70TG mice were activated and increased in numbers, in particular the pool of inflammatory $\left(\mathrm{Ly}_{6 \mathrm{C}}{ }^{+}\right)$monocytes. Importantly, monocytes from CD70TG mice had no defects in phagocytosis nor in TNF $\alpha$ production, but they were more prone to apoptosis, which was IFN $\gamma$-dependent. These data indicate that sterile pro-inflammatory conditions can be protective against atherosclerosis
\end{abstract}

development, possibly due to a reduced viability of circulating monocytes. This unexpected outcome provides a new insight into the consequences of costimulatory signals and their impact on innate immunity.

Copyright $\odot 2010$ S. Karger AG, Basel

\section{Introduction}

Infection and inflammation are strongly implicated in the progression of atherosclerotic disease. A role for inflammation in the pathogenesis of this process is supported by the presence of monocytes/macrophages and $\mathrm{T}$ cells in atherosclerotic plaques. Furthermore, a large number of studies in humans and animal models has demonstrated that infection with persistent pathogens is associated with an increased risk of vascular disease (reviewed in [1-3]). Infectious pathogens may affect atherosclerotic disease in several, not mutually exclusive, ways. First, pathogens may infect cells residing in lesions (e.g. endothelial cells), thereby causing alterations of cellular function or even cell destruction. Second, antigens delivered by microbes will activate specific $\mathrm{T}$ and $\mathrm{B}$ cells that may cross-react with (altered) self-antigens, such as modified lipo-proteins, present in the lesions. In this scenario, part of the progression of vascular disease takes place via

\section{KARGER}

Fax +4161306 1234

E-Mail karger@karger.ch

www.karger.com (c) 2010 S. Karger AG, Basel

1662-811X/10/0024-0344\$26.00/0

Accessible online at:

www.karger.com/jin
Dr. Martijn A. Nolte

Department of Experimental Immunology

Academic Medical Center, University of Amsterdam, Meibergdreef 9

NL-1105 AZ Amsterdam (The Netherlands)

Tel. +31 20566 2226, Fax +31 20566 9756, E-Mail m.a.nolte@amc.nl 
specific (auto-)immune reactions. Third, pathogens will, via the activation of the innate and adaptive immune system, induce systemic inflammation resulting in increased plasma levels of inflammatory cytokines, together with enhanced numbers of effector T cells. Both soluble and cellular mediators of immunity localize in the atherosclerotic plaques and amplify the inflammatory process in an antigen non-specific fashion [4].

To test the influence of immune activation on the development of atherosclerosis without the confounding effects of infectious agents, we examined atherosclerosis development in a murine model of sterile T cell-mediated immune activation, driven by overexpression of the costimulatory molecule CD70. This member of the TNFsuperfamily is normally only transiently expressed on activated T cells, B cells and dendritic cells (reviewed in [5]) and under these conditions it provides important prosurvival signals to $\mathrm{T}$ cells through its receptor CD27 [6, 7]. We have previously shown that transgenic overexpression of CD70 on B cells is sufficient to induce strong T cell activation and a concomitant increase of IFN $\gamma$-producing effector $\mathrm{T}$ cells, which provides protection against a challenge with influenza virus as well as tumor cells $[8$, 9]. However, there is also a severe downside of this enhanced immune activation, as these CD70-transgenic (CD70TG) mice gradually lose their B cells due to the chronic exposure to IFN $\gamma$ [8], and in the long term even exhaust their naïve $\mathrm{T}$ cell pool [10]. We used this noninfectious model of chronic immune activation to determine whether persistent sterile inflammation is sufficient to enhance the development of atherosclerosis.

\section{Materials and Methods}

Mice

B cell-specific CD70TG mice, IFN $\gamma^{-/-}$and CD70TGxIFN $\gamma^{-/-}$ mice [8], as well as ApoE*3-Leiden mice [11], all on a C57Bl/6 background, were maintained at the animal department of the Academic Medical Center (Amsterdam, The Netherlands) and used for experiments between 8-12 weeks of age. Non-transgenic littermates were used as controls. For the induction of atherosclerosis, CD70TG mice were backcrossed on a ApoE*3-Leiden background. Identification of mutant mice was performed by PCR analysis of tail DNA or by FACS analysis of peripheral blood cells. From these crosses, only female ApoE*3-Leiden ${ }^{+}$littermate (WT and CD70 TG) mice were used, and from the age of 8 weeks these mice were fed a high cholesterol/fat diet (1\% cholesterol/18\% fat, Purif Diet W, 4021.36, Hope Farms, The Netherlands) for 12, 16 or 20 weeks. All mice were handled in accordance with institutional and national guidelines and all experimental protocols were approved by the institutional ethics committee for animal experiments.

Protection against Atherosclerosis during Chronic Inflammation
Antibodies and Flow Cytometry

Antibodies used in this study were obtained from the following sources. Pharmingen: allophycocyanin (APC)-conjugated anti-CD11b (clone M1/70), PE-conjugated anti-Fas (clone Jo2) and PE- or APC-conjugated anti-CD62L (clone MEL-14). eBioscience: FITC-conjugated anti-F4/80 (clone BM8) and PerCP-Cy5.5-conjugated anti-Ly6C (clone HK1.4). Sanbio: PE-conjugated anti-CX${ }_{3}$ CR1 (clone 2A9-1). Antibodies against CCR5 (clone MC-68, a kind gift from Dr. Matthias Mack), CD11a (clone H154.163; a kind gift from Dr. Yvette van Kooyk) and MHC class II (clone M5-114) were purified from hybridoma supernatants. Anti-MHC class II was conjugated to biotin according to standard procedures and detected with streptavidin-PerCP-Cy5.5 (Pharmingen), while PE- or FITC-conjugated donkey anti-rat (Jackson) was used to detect non-conjugated antibodies. When possible, Fc-receptormediated binding was blocked by co-incubation with anti-Fc $\gamma$ RII/III receptor (clone 2.4G2; kind gift from Dr. Louis Boon, Bioceros, Utrecht, The Netherlands).

Blood $( \pm 700 \mu \mathrm{l})$ was obtained by heart puncture and mixed with $10 \mu \mathrm{l}$ heparine $(5,000 \mathrm{IE} / \mathrm{ml}$, LEO Pharma). Upon lysis of erythrocytes with an ammonium chloride solution, white blood cells were resuspended in staining buffer (PBS with $0.5 \%$ bovine serum albumin) and stained with antibodies for $30 \mathrm{~min}$ at $4{ }^{\circ} \mathrm{C}$ in a 96-well V-bottomed plate. For analysis of apoptosis, cells were incubated for $30 \mathrm{~min}$ at $37^{\circ} \mathrm{C}$ with Mitotracker Orange $(250 \mathrm{nM}$; Invitrogen). For TNF $\alpha$ stainings, $100 \mu \mathrm{l}$ of heparinized blood was cultured for $4 \mathrm{~h}$ at $37^{\circ} \mathrm{C}$ with LPS $(1,875 \mu \mathrm{g} / \mathrm{ml})$ or PMA $(1 \mathrm{ng} / \mathrm{ml})$ and ionomycin $(1 \mu \mathrm{M})$ in the presence of brefeldin $\mathrm{A}(1 \mu \mathrm{g} / \mathrm{ml}$; all reagents obtained from Sigma). After lysis of erythrocytes, cells were washed and stained with antibodies against F4/80 and CD11b, followed by fixation and permeabilization (Cytofix/Cytoperm; BD Biosciences) and staining for $\mathrm{TNF} \alpha$. Data acquisition was done with a FACSCalibur or FACS Canto (BD) and data were analyzed with Flowjo software (Tree Star).

\section{Phagocytosis Assay and Foam Cell Formation}

To determine the phagocytic capacity of blood monocytes, 100 $\mu \mathrm{l}$ heparinized blood was cultured for $3 \mathrm{~h}$ at $37^{\circ} \mathrm{C}$ in a total volume of $1 \mathrm{ml}$ Iscove's modified Dulbecco's medium (IMDM) + $10 \%$ FCS in the presence or absence of DiI-labeled oxidized LDL $(5 \mu \mathrm{g} / \mathrm{ml}$, Intracel) or FITC-conjugated zymosan [5 mg/ml sterilized zymosan (Sigma) was incubated with $2.5 \mu \mathrm{g} / \mathrm{ml}$ filter-sterilized FITC (Sigma) for $45 \mathrm{~min}$ at RT, subsequently washed with sterile PBS and stored at $-20^{\circ} \mathrm{C}$. Next, cells were washed, erythrocytes were lysed with an ammonium chloride solution and leukocytes were subsequently stained for analysis by flow cytometry as described above.

For foam cell formation, erythrocytes were lysed from fresh blood and the remaining cell fraction was cultured in IMDM $/ 10 \%$ FCS on coverslips in the presence of $100 \mu \mathrm{g} / \mathrm{ml}$ ox-LDL (RP-047, Intracel). After 5 days of culture, coverslips were washed, fixed with $3.5 \%$ formaldehyde, stained with oil red O (Sigma) and counterstained with hematoxylin, both according to standard protocols. Foam cells, identified as large cells laden with red lipid droplets, were counted and analyzed for morphology with light microscopy.

\section{Serum Cholesterol Analysis}

Mice underwent a fasting period of 4-12 h after which blood was isolated. The concentrations of total cholesterol in the serum 
were determined according to the manufacturer's instructions (bioMerieux). A cholesterol calibrator (standardized serum; bioMerieux) was used as internal standard.

Measurement of Oxidized LDL Antibodies

To determine anti-oxidized LDL antibodies in serum, 96-well plates were coated overnight at $4{ }^{\circ} \mathrm{C}$ with oxidized LDL $(10 \mu \mathrm{g} / \mathrm{ml}$, $\mathrm{RP}-047$, Intracel $)$ in coating buffer $\left(0.1 \mathrm{M} \mathrm{NaH}_{4} \mathrm{CO}_{3}\right)$. Subsequently, plates were blocked with 5\% BSA for $2 \mathrm{~h}$ at RT. Sera from CD70TG $\times$ ApoE*$^{*} 3$-Leiden and ApoE*3-Leiden mice were added into duplicate wells in various dilutions and incubated for $2 \mathrm{~h}$ at RT. Plates were subsequently incubated with a biotin-conjugated goat anti-mouse IgG (1034-08, SBA), followed by an incubation with streptavidin-conjugated horse radish peroxidase (P0397, DAKO). Between the various steps the plate underwent extensive washing. Finally, plates were developed with $50 \mu$ l substrate [10 $\mathrm{ml} \mathrm{NaAc}, 100 \mu \mathrm{l}$ tetramethylbenzidine $(6 \mathrm{mg} / \mathrm{ml}$ in DMSO, VWR), $10 \mu \mathrm{l} 3 \% \mathrm{H}_{2} \mathrm{O}_{2}$ ] and terminated with $2 \mathrm{~N} \mathrm{H}_{2} \mathrm{SO}_{4}$. Optical density was measured at 450 and $540 \mathrm{~nm}$ using a microplate reader.

\section{Histological Analysis of Hearts and Aortas}

Atherosclerotic lesion development was analyzed after completion of the high cholesterol/fat diet. Mice were anesthetized and perfused with PBS for 10 min via a cannula in the left ventricle, followed by a 10 -min post-perfusion fixation with $1 \%$ neutral-buffered formalin (Formal-Fix, Shandon Scientific) and subsequent storage of the hearts and aortas in formalin. Hearts were bisected at the level of the atria and the base of the heart was taken for analysis. Cryostat 7- $\mu \mathrm{m}$ cross-sections of the aortic root were made and stained with oil red O (Sigma). Quantification of the atherosclerotic lesion area in the sections was performed on total plaque area, using Q-win analysis (Leica). The mean lesion area was calculated (in $\mu \mathrm{m}^{2}$ ) from ten sections, starting at the appearance of the tricuspid valves.

\section{Statistical Analysis}

For measurement of lesion size and serum cholesterol levels at different time points, we used a 2-way ANOVA with Bonferroni post-tests and area under the curve analysis to compare anti-oxidized LDL antibodies in serum. For comparison of cell surface marker expression between 4 different groups of mice we used a 1-way ANOVA with Bonferroni posttests. For all other analyses, we used an unpaired Student's t test, in which $\mathrm{p}<0.05$ was considered to be significantly different. For all statistical tests we made use of GraphPad Prism 5 software.

\section{Results}

\section{CD70TG Mice Are Protected against Atherosclerosis}

To examine the extent by which chronic immune activation could affect atherosclerotic plaque development, we crossed CD70TG mice with atherosclerosis-prone ApoE*3-Leiden mice. ApoE*3-Leiden mice build up severe hypercholesterolemia following a high cholesterol/ fat diet, leading to atherosclerotic lesions in the aorta and


ApoE*3-Leiden control mice were analyzed for vascular lesion formation in the aortic root after a 12-, 16- or 20week period of high cholesterol/fat-diet. In contrast to what we expected, CD70TG $\times$ ApoE*3-Leiden mice $^{*}$ were fully protected against atherosclerosis development, while control ApoE*3-Leiden mice did develop large atherosclerotic lesions (fig. 1a, b). Both groups of mice did develop diet-induced hypercholesterolemia, although serum cholesterol levels were slightly lower in CD70TG $\times$ ApoE*3-Leiden compared to ApoE*3-Leiden control mice (fig. 1c; $p=0.026$ in a 2-way ANOVA between the two groups of mice, but no statistical differences per time point); however, this small difference in cholesterol level is not sufficient to explain the large difference in atherosclerosis development between these mice. As the production of antibodies against oxidized LDL (ox-LDL) plays an important protective role in initiation of atherosclerosis $[12,13]$, we tested whether the observed protection against atherosclerosis could be explained by an increase of these athero-protective antibodies. However, we found a strongly reduced production of anti-ox-LDL an-

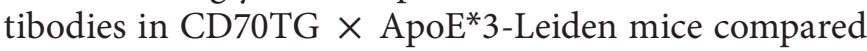
to $\mathrm{ApoE}^{*} 3$-Leiden mice [area under the curve (average \pm SD) $=3,808 \pm 312$ vs. $20,920 \pm 6,347, \mathrm{p}<0.01$; fig. 1e], which correlated with a profound $B$ cell depletion in these mice (fig. 1d). Thus, despite the development of strong pro-atherogenic features, CD70-mediated chronic inflammation induced a sustained protective effect against the development of atherosclerosis.

\section{CD70 Overexpression Induces Monocyte \\ Accumulation and Activation}

Since monocytes/macrophages play an important role in the development of atherosclerosis, we tested whether circulating monocytes were affected in CD70TG mice, as a defect in this cellular compartment could explain the observed protection against atherosclerosis (reviewed in [14]). Yet, we found that CD70TG mice had even more monocytes, defined as Sideward Scatter ${ }^{\mathrm{lo}} \mathrm{CD} 11 \mathrm{~b}^{\mathrm{hi}} \mathrm{F} 4 / 80^{+}$ cells, in peripheral blood than WT controls, not only percentage wise (fig. 2a) but also in absolute numbers (fig. 2b). Moreover, these monocytes had an activated phenotype, based on the high expression of MHC class II (fig. 2c), which was a direct effect of the enhanced production of IFN $\gamma$ in these mice, as it could not be seen in CD70TG mice that were backcrossed on an IFN $\gamma$-deficient background (fig. 2c). To substantiate the activation state of these cells, we examined more features of cellular activation. Indeed, monocytes in CD70TG mice had increased 


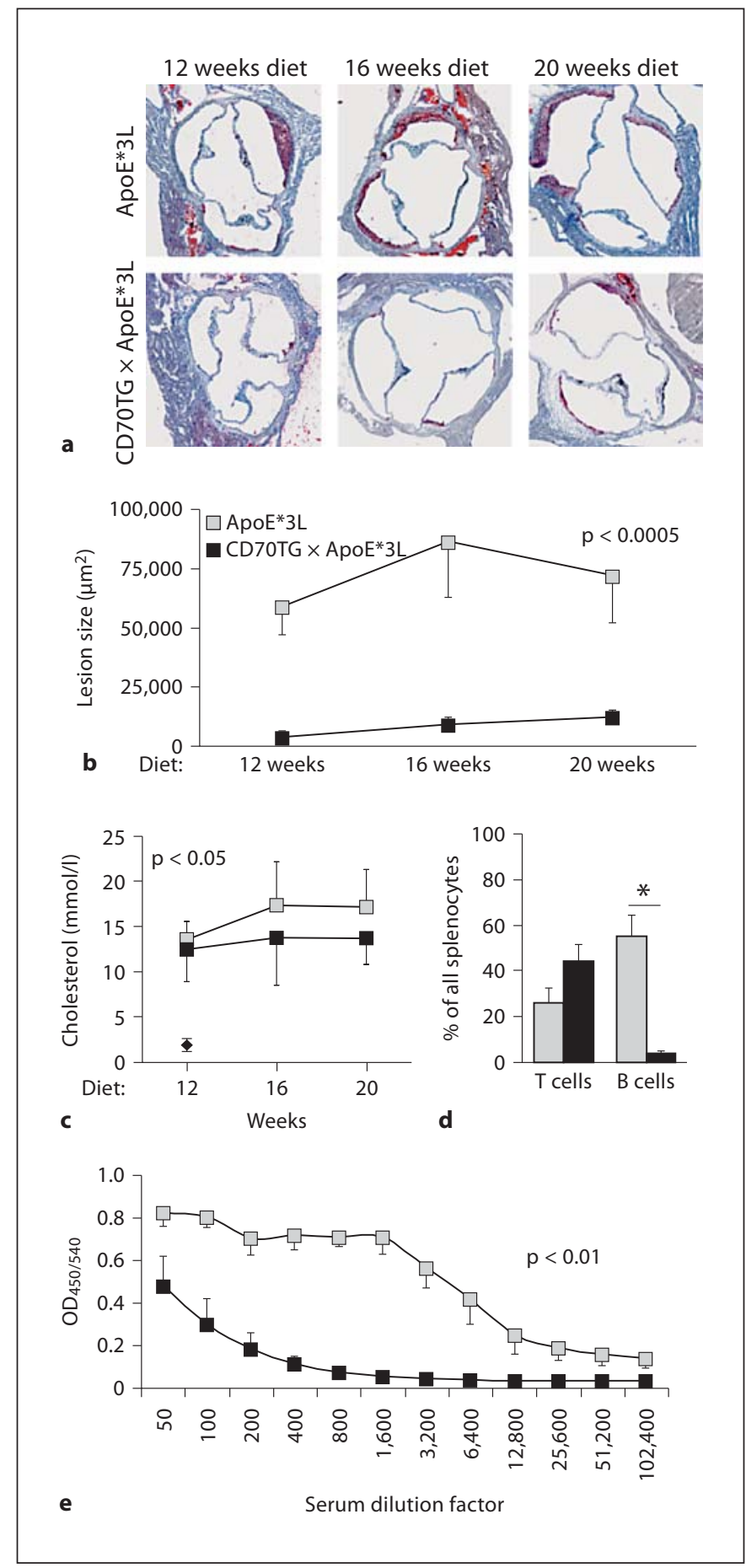

Fig. 1. CD70 overexpression is protective for development of atherosclerotic lesions. a Representative lipid stainings (in red) of the aortic roots of ApoE*3-Leiden and CD70TG $\times$ ApoE*3-Leiden mice after 12, 16 and 20 weeks of cholesterol-rich diet. b Average atherosclerotic lesion area in the aortic roots (performed on total plaque area). c Average serum cholesterol levels of ApoE*3-Leiden (grey) and CD70TG $\times$ ApoE $^{*} 3$-Leiden mice (black). Black dia- expression of CD95 (Fas), CCR5 (receptor for the inflammatory chemokines MIP-1 $\alpha / \beta$, RANTES and MCP-2), $\mathrm{CX}_{3} \mathrm{CR} 1$ (receptor for the inflammatory chemokine fractalkine) and CD11a (the $\alpha$ chain of the $\beta 2$-integrin LFA-1; fig. 2d), which are all upregulated on monocytes during activation. This increase in monocyte activation was due to an increase in IFN $\gamma$ production, as it was absent in $\mathrm{CD} 70 \mathrm{TG} \times \mathrm{IFN}^{-1-}$ mice (fig. $2 \mathrm{~d}$ ).

Circulating monocytes can be separated in two distinct subsets based on Ly6C expression, which have been attributed different functions: Ly6C ${ }^{\text {hi }} \mathrm{CD} 62 \mathrm{~L}^{+}$monocytes are regarded as inflammatory monocytes that are actively recruited to inflamed tissues, whereas $\mathrm{Ly}_{6} \mathrm{C}^{\mathrm{lo}} \mathrm{CD} 62 \mathrm{~L}^{-}$ monocytes migrate to non-inflamed tissues to differentiate into resident macrophages [15]. In a pro-atherogenic setting, Ly $6 \mathrm{C}^{\text {hi }}$ monocytes are recruited to atherosclerotic plaques and locally develop into lipid-laden macrophages and are hence recognized as the key monocyte subset in the development of atherosclerosis $[16,17]$. Intriguingly, we found that the increase in monocytes in CD70TG mice was due to a rise in Ly6 $\mathrm{C}^{\text {hi }}$ monocytes, whereas the number of Ly6 $\mathrm{C}^{\text {lo }}$ cells was not altered (fig. 2e, f). Thus, these data demonstrate that CD70TG mice have high numbers of activated, inflammatory monocytes in circulation.

\section{Monocytes from CD70TG Mice Have No Defect in \\ Phagocytosis nor TNF $\alpha$ Production}

Next, we examined if the enhanced activation state of circulating monocytes in CD70TG mice was accompanied by changes in monocyte function. First, the phagocytic capacity of these cells was measured in vitro, by culturing full blood from WT and CD70TG mice in the presence of ox-LDL or zymosan (heat-killed yeast particles). We found that monocytes from CD70TG mice phagocytosed ox-LDL and zymosan equally well, if not better, than WT monocytes (fig. 3a, b). Moreover, 5-day cultures of monocytes with ox-LDL also indicated that monocytes from CD70TG mice could develop normally into foam cells (data not shown). Finally, we determined

mond symbol indicates serum cholesterol of control mice fed normal chow for 12 weeks. d Average percentage of splenic T and B cells in ApoE*3-Leiden (grey) and CD70TG $\times$ ApoE*3-Leiden mice (black). ${ }^{*} \mathrm{p}<0.05$, by Student's t test. e Serum levels of antibodies against ox-LDL in ApoE*3-Leiden (grey) and CD70TG $\times$ ApoE*3-Leiden mice (black). In all panels, error bars indicate the standard deviation of 8-10 mice per group. 


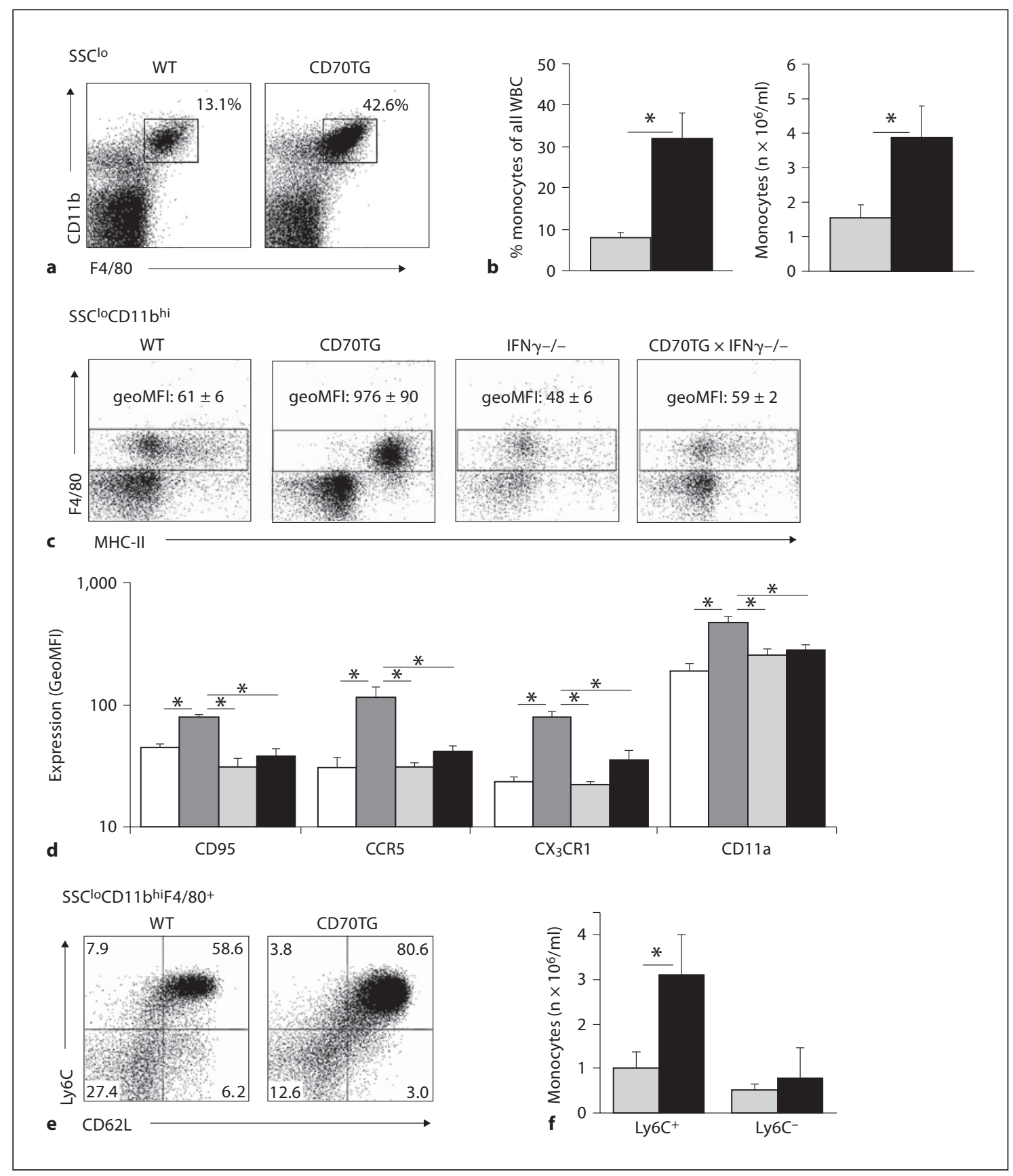

Fig. 2. CD70TG mice have increased numbers of activated circulating monocytes. a Representative staining for monocytes $\left(\mathrm{CD} 11 \mathrm{~b}^{\text {hi }} \mathrm{F} 4 / 80^{+}\right.$cells) in peripheral blood of WT and CD70TG mice, gated on SSC ${ }^{\text {lo }}$ cells to exclude $\mathrm{F} 4 / 80^{+}$eosinophils. b Relative and absolute numbers (per $\mathrm{ml}$ ) of monocytes in peripheral blood in WT (grey bars) and CD70TG mice (black bars). c Representative staining for MHC class II expression on monocytes in peripheral blood, gated on SSClo $C D 11 b^{\text {hi }}$ cells. Average geometric mean fluorescent intensity (geoMFI) for MHC class II expression on the gated $\mathrm{F} 4 / 80^{+}$monocytes is indicated. $\mathbf{d}$ Mean expression of several activation-dependent cell surface molecules on peripheral blood monocytes in WT (white bars), CD70TG (dark grey bars), IFN $\gamma^{-/-}$(light grey bars) and CD70TG $\times$IFN $\gamma^{-/-}$mice (black bars). e Representative staining for Ly6C and CD62L on peripheral blood monocytes (gated on SSC ${ }^{\mathrm{lo}} \mathrm{CD} 11 \mathrm{~b}^{\text {hi }} \mathrm{F} 4 / 80^{+}$cells). f Absolute numbers (per $\mathrm{ml}$ of blood) of Ly6 $\mathrm{C}^{+}$and $\mathrm{Ly} 6 \mathrm{C}^{-}$monocytes (as defined above) in WT (grey bars) and CD70TG mice (black bars). Shown are averages \pm standard deviation of 3 mice per group. In $\mathbf{b}$ and $\mathbf{f}$ asterisks denote a significant difference $(\mathrm{p}<$ 0.01 ) as determined by Student's t test, while in $\mathbf{d}$ they denote a significant difference $(\mathrm{p}<0.05)$ as determined by a 1-way ANOVA with Bonferroni post-tests. 
Fig. 3. Monocytes of CD70TG mice can phagocytose and produce large amounts of TNF $\alpha$. Uptake of DiI-labeled ox-LDL (a) or FITC-labeled zymosan (b) by $\mathrm{CD} 11 \mathrm{~b}^{\text {hi }} \mathrm{F} 4 / 80^{+}$monocytes after $3 \mathrm{~h}$ incubation at $37^{\circ} \mathrm{C}$ of full blood from WT (dotted line) or CD70TG mice (black line) in the absence (control; filled grey histogram) or presence of the indicated compounds. Data are representative stainings of two independent experiments of three mice per group. TNF $\alpha$ expression (in GeoMFI) in CD $11 b^{\text {hi }} \mathrm{F} 4 / 80^{+}$monocytes from WT (grey bars) and CD70TG mice (black bars) after $3 \mathrm{~h}$ stimulation with LPS (c) or PMA/ionomycin (d) in the presence of Brefeldin A. Bars indicate average \pm standard deviation of 3 mice per group. ${ }^{*} \mathrm{p}<0.01$, by Student's t test.
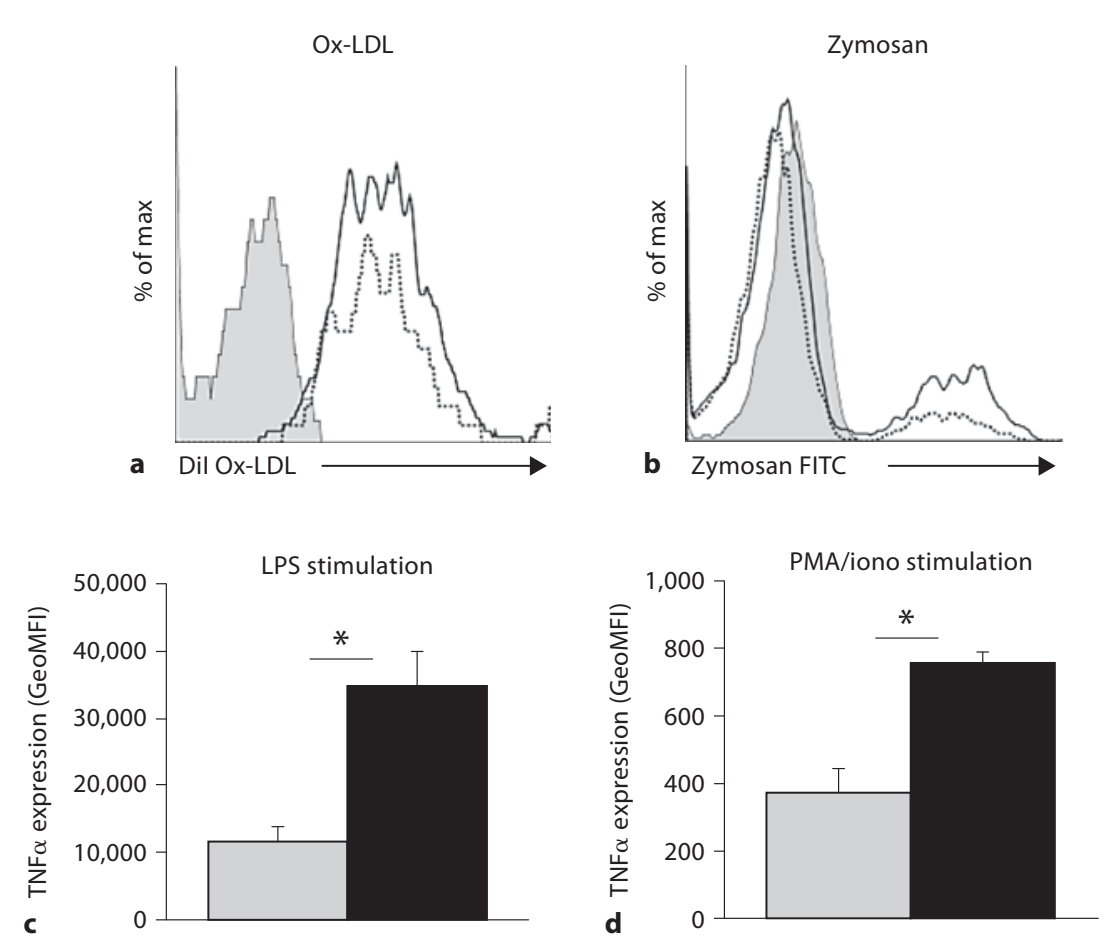

whether monocytes in CD70TG mice could still produce $\mathrm{TNF} \alpha$, since this pro-inflammatory cytokine is a potent activator of endothelial cells and a key factor in the development of atherosclerosis $[18,19]$. We found that CD70TG mice were not defective in their production of TNF $\alpha$ and even produced more TNF $\alpha$ per cell than WT mice, when stimulated with either LPS (fig. 3c) or PMA/ionomycin (fig. 3d).

\section{Monocytes from CD70TG Mice Are More Susceptible to Apoptosis}

Since monocytes in CD70TG mice are more activated and express a higher level of CD95 (fig. 2d), we considered the possibility that chronic immune activation affected the viability of these cells. Therefore, we cultured full blood of WT and CD70TG mice overnight and determined cellular viability the next day by measuring the mitochondrial membrane potential, as this potential is rapidly lost when cells go into apoptosis [20]. Although no major differences could be observed in cellular viability when measured directly ex vivo (data not shown), we found that CD70TG-derived monocytes died more rapidly than cells from WT mice and that this feature was specific for monocytes, as we found no difference for granulocytes in these same cultures (fig. 4a, b). This increased apoptosis susceptibility was seen in monocytes from CD70TG mice, but not from CD70TG $\times$ IFN $\gamma^{-/-}$ mice, thus demonstrating that this process was dependent on IFNy (fig. 4a, b). Finally, we tested whether the enhanced propensity to die was intrinsic to the monocytes and therefore we sorted Ly6 $6 \mathrm{C}^{\text {hi }}$ and Ly $6 \mathrm{C}^{\text {lo }}$ monocytes from peripheral blood of both mice. Upon overnight culture, we observed an increase in monocyte apoptosis in both populations of CD70TG mice, measured either with Mitotracker to determine mitochondrial membrane potential (fig. 4c) or with propidium iodide to test cell membrane integrity (fig. $4 \mathrm{~d}$ ). These findings demonstrate that the enhanced susceptibility to apoptosis is indeed cell-intrinsic and affects both Ly6C hi and Ly6C ${ }^{\text {lo }}$ monocyte subsets in CD70TG mice.

\section{Discussion}

Although chronic immune responses to persistent pathogens are associated with an increased risk of atherosclerosis, most likely due to the chronic and bi-directional activation of cells from the innate and acquired im- 




Fig. 4. Monocytes from CD70TG mice are more prone to apoptosis. a Representative staining for mitochondrial potential with Mitotracker for monocytes $\left(\mathrm{CD} 11 \mathrm{~b}^{+} \mathrm{F} 4 / 80^{+}\right)$and granulo-

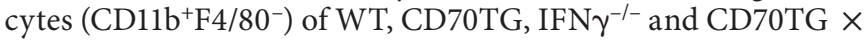
IFN $\gamma^{-1-}$ mice after overnight culture in full blood; percentages of live (Mitotracker ${ }^{\text {hi }}$ ) cells are indicated. b Average percentage of live (Mitotracker ${ }^{\text {hi }}$ ) cells within the monocyte and granulocytes fraction after overnight culture for WT (white bars), CD70TG (dark grey bars), IFN $\gamma^{-/-}$(light grey bars) and CD70TG $\times$ IFN $\gamma^{-/-}$mice (black bars). Error bars indicate the standard deviation of 3 mice per group. ${ }^{*} p<0.01$, by Student's t test. c, $\mathbf{d}$ Representative staining for mitochondrial potential using Mitotracker (c) or cell permeability using propidium iodide (d) of sorted Ly6C $\mathrm{C}^{+}$ and $\mathrm{Ly} 6 \mathrm{C}^{-}$peripheral blood monocytes from WT and CD70TG mice after overnight culture. Percentages of live monocytes are indicated. 
mune system, we show here that sterile chronic immune activation driven by enhanced expression of CD70 is in fact highly protective against atherosclerosis. This would suggest that the anti-pathogenic response itself, rather than the ensuing chronic inflammatory response plays an important role. It would therefore be interesting to determine atherosclerotic susceptibility of CD70TG mice that are chronically infected with a persistent pathogen, such as murine cytomegalovirus or lymphocytic choriomeningitis virus. Yet this approach does require that these mice do not clear the virus, which is not trivial as CD70TG mice did display increased anti-viral responses against infection with influenza virus [9]. From a different perspective, it would also be interesting to test whether overexpression of other TNF-superfamily members, which generally leads to sterile chronic immune activation as well (summarized in [5]), also induces protection against atherosclerosis. This might enable us to unravel the molecular pathways that underlie the observed effects and establish whether they can be generalized to chronic immune activation or are specific to CD27-CD70 interactions.

Development of atherosclerotic plaques is driven by the recruitment of monocytes to the intima of inflamed blood vessels, which is mediated by activated endothelial cells and locally produced chemokines. Many studies have shown that defects in this recruitment can prevent the onset of atherosclerosis (reviewed in [4]) and it has also been shown that CCR5, $\mathrm{CX}_{3} \mathrm{CR} 1$ and CCR2 are all required for the transendothelial migration of Ly $6 \mathrm{C}^{\text {hi }}$ monocytes in atherosclerosis $[17,21]$. Yet we observed no defects in the expression of these receptors on monocytes in CD70TG mice and even found that expression of CCR 5 and $\mathrm{CX}_{3} \mathrm{CR} 1$ was increased (fig. 2d). CCR2 was not differentially expressed and in vitro transwell migration assays with its ligand MCP-1 also showed no differences compared to WT controls (data not shown). Furthermore, $\mathrm{CD} 62 \mathrm{~L}$ and $\beta 2$-integrins, required for rolling and firm adhesion, respectively, were not differentially expressed on monocytes from CD70TG mice (fig. 2). These data make it highly unlikely that a defect in transendothelial migration of monocytes is the cause of the observed atheroprotective effect in these mice.

Previous experiments with CD70TG mice have revealed that production of IFN $\gamma$ by $\mathrm{T}$ cells plays an important role in the phenotype of these mice, in particular the gradual loss of B cells [8]. Although serum levels of IFN $\gamma$ are below the detection limit in CD70TG mice (data not shown), the dramatic B cell loss was still observed on the ApoE*3-Leiden background, which indicates that IFN $\gamma$ is also increased in this compound model. We demonstrate that IFN $\gamma$ is responsible for the activated phenotype as well as the increased apoptosis susceptibility of monocytes from CD70TG mice (fig. $2 \mathrm{~d}$ and $4 \mathrm{a}, \mathrm{b}$ ); this is important as it also demonstrates that triggering of CD27 on hematopoietic progenitor cells and subsequent changes in hematopoiesis [22] are not the cause of the observed phenotype. Importantly, overnight incubation of WT monocytes with IFN $\gamma$ was not sufficient to induce monocyte apoptosis (data not shown), which means that the IFN $\gamma$ activated environment of the CD70TG mice increases their sensitivity to apoptosis, rather than the exposure to IFN $\gamma$ itself. Expression of the death receptor CD95 (FAS) was upregulated on monocytes from CD70TG mice in an IFN $\gamma$-dependent manner (fig. $2 \mathrm{~d}$ ), but we were unable to prevent apoptosis with blocking antibodies against CD95L (FASL), nor with the pan-caspase inhibitor QVD (data not shown). Although the mode of apoptosis of CD70TG-derived monocytes remains elusive at this stage, it is conceivable that the underlying mechanism plays an important role in the protection against atherosclerosis seen in CD70TG mice, especially since selective depletion of monocytes/macrophages is sufficient to inhibit early atherogenesis [23]. Premature monocyte death upon entry into the premature lesion will preclude accumulation of pro-inflammatory macrophages and dendritic cells and thereby prevent or at least attenuate subsequent development of the atherosclerotic plaque [24, 25]. Examining atherosclerosis development in CD70TG mice in the absence of chronic exposure to IFN $\gamma$ would therefore be a very attractive idea to examine the contribution of IFN $\gamma$ in this process, but these experiments are hampered by the fact that IFN $\gamma$ is essential for monocyte maturation and thereby indispensable for the development of atherosclerotic lesions in this model [26]. Moreover, it has been shown that TNF $\alpha$-deficient mice have a reduced percentage of apoptotic cells inside atherosclerotic lesions [27], which could indicate that the enhanced TNF $\alpha$ production of monocytes in CD70TG mice (fig. 3c, d) also plays an important role in the increased level of apoptosis, thereby inhibiting lesion development. However, neutralizing antibodies against TNF $\alpha$ in the in vitro cultures could not prevent the increased monocyte apoptosis (data not shown), which makes it difficult to substantiate this hypothesis. Further investigation is required to assess whether the pro-apoptotic profile of CD70TG-derived monocytes is indeed causally related to the observed protection against atherosclerosis of these mice.

In conclusion, despite the prevailing notion that chronic inflammatory conditions are contributing to the 
development of atherosclerotic lesions, we describe here a model of costimulation-driven chronic immune activation that is highly protective against the development of this disease, despite the occurrence of several pro-atherogenic features. It will be important to establish the nature of this strongly protective mechanism and to investigate whether it can be exploited for future therapeutic use.

\section{Acknowledgments}

We thank Sten Libregts and Dr. Klaas van Gisbergen for technical assistance, and the staff of the animal facility of the AMC for excellent animal care. C.J.M.d.V. was supported by the Netherlands Heart Foundation (grant No. 2008B037). M.A.N. and R.A.W.v.L. were respectively supported by a VIDI and a VICI grant from the Netherlands Organization of Scientific Research.

\section{References}

1 Becker AE, de Boer OJ, van der Wal AC: The role of inflammation and infection in coronary artery disease. Ann Rev Med 2001;52: 289-297.

-2 Epstein SE, Zhu J, Burnett MS, Zhou YF, Vercellotti G, Hajjar D: Infection and atherosclerosis: potential roles of pathogen burden and molecular mimicry. Arterioscler Thromb Vasc Biol 2000;20:1417-1420.

$>3$ Leinonen $M$ and Saikku P: Evidence for infectious agents in cardiovascular disease and atherosclerosis. Lancet Infect Dis 2002;2:1117.

4 Hansson GK, Libby P: The immune response in atherosclerosis: a double-edged sword. Nat Rev Immunol 2006;6:508-519.

$>5$ Nolte MA, van Olffen RW, van Gisbergen $\mathrm{KP}$, van Lier RA: Timing and tuning of CD27-CD70 interactions: the impact of signal strength in setting the balance between adaptive responses and immunopathology. Immunol Rev 2009;229:216-231.

6 Hendriks J, Xiao Y, Borst J: CD27 promotes survival of activated $\mathrm{T}$ cells and complements CD28 in generation and establishment of the effector T cell pool. J Exp Med 2003;198:1369-1380.

7 Peperzak V, Xiao Y, Veraar EA, Borst J: CD27 sustains survival of CTLs in virus-infected nonlymphoid tissue in mice by inducing autocrine IL-2 production. J Clin Invest 2010; 120:168-178.

$>8$ Arens R, Tesselaar K, Baars PA, van Schijndel GM, Hendriks J, Pals ST, Krimpenfort P, Borst J, van Oers MH, van Lier RA: Constitutive CD27/CD70 interaction induces expansion of effector-type $\mathrm{T}$ cells and results in IFNgamma-mediated B cell depletion. Immunity 2001; 15:801-812.

$\checkmark 9$ Arens R, Schepers K, Nolte MA, van Oosterwijk MF, van Lier RA, Schumacher TN, van Oers MH: Tumor rejection induced by CD70-mediated quantitative and qualitative effects on effector CD8+ T cell formation. J Exp Med 2004;199:1595-1605.
10 Tesselaar K, Arens R, van Schijndel GM, Baars PA, van d, V, Borst J, van Oers MH, van Lier RA: Lethal T cell immunodeficiency induced by chronic costimulation via CD27CD70 interactions. Nat Immunol 2003;4: 49-54.

11 van Vlijmen BJ, van den Maagdenberg AM, Gijbels MJ, van der Boom $\mathrm{H}$, HogenEsch $\mathrm{H}$, Frants RR, Hofker MH, Havekes LM: Dietinduced hyperlipoproteinemia and atherosclerosis in apolipoprotein E3-Leiden transgenic mice. J Clin Invest 1994;93:1403-1410.

$>12$ Caligiuri G, Nicoletti A, Poirier B, Hansson GK: Protective immunity against atherosclerosis carried by B cells of hypercholesterolemic mice. J Clin Invest 2002;109:745-753.

13 Major AS, Fazio S, Linton MF: B-lymphocyte deficiency increases atherosclerosis in LDL receptor-null mice. Arterioscler Thromb Vasc Biol 2002;22:1892-1898.

14 Galkina E, Ley K: Immune and inflammatory mechanisms of atherosclerosis. Annu Rev Immunol 2009;27:165-197.

15 Geissmann F, Jung S, Littman DR: Blood monocytes consist of two principal subsets with distinct migratory properties. Immunity 2003; 19:71-82.

16 Swirski FK, Libby P, Aikawa E, Alcaide P, Luscinskas FW, Weissleder R, Pittet MJ: Ly6Chi monocytes dominate hypercholesterolemia-associated monocytosis and give rise to macrophages in atheromata. J Clin Invest 2007; 117:195-205.

17 Tacke F, Alvarez D, Kaplan TJ, Jakubzick C, Spanbroek R, Llodra J, Garin A, Liu J, Mack M, van Rooijen N, Lira SA, Habenicht AJ, Randolph GJ: Monocyte subsets differentially employ CCR2, CCR5, and CX3CR1 to accumulate within atherosclerotic plaques. J Clin Invest 2007;117:185-194.

18 Boesten LS, Zadelaar AS, van NA, Gijbels MJ, de Winther MP, Havekes LM, van Vlijmen BJ: Tumor necrosis factor-alpha promotes atherosclerotic lesion progression in APOE*3-Leiden transgenic mice. Cardiovasc Res 2005;66:179-185.
19 Ohta H, Wada H, Niwa T, Kirii H, Iwamoto N, Fujii H, Saito K, Sekikawa K, Seishima M: Disruption of tumor necrosis factor-alpha gene diminishes the development of atherosclerosis in ApoE-deficient mice. Atherosclerosis 2005; 180:11-17.

20 Poot M, Gibson LL, Singer VL: Detection of apoptosis in live cells by MitoTracker red CMXRos and SYTO dye flow cytometry. Cytometry 1997;27:358-364.

-21 Gautier EL, Jakubzick C, Randolph GJ: Regulation of the migration and survival of monocyte subsets by chemokine receptors and its relevance to atherosclerosis. Arterioscler Thromb Vasc Biol 2009;29:1412-1418.

22 Nolte MA, Arens R, van Os R, van Oosterwijk M, Hooibrink B, van Lier RA, van Oers MH: Immune activation modulates hematopoiesis through interactions between CD27 and CD70. Nat Immunol 2005;6:412-418.

23 Stoneman V, Braganza D, Figg N, Mercer J, Lang R, Goddard M, Bennett M: Monocyte/ macrophage suppression in CD11b diphtheria toxin receptor transgenic mice differentially affects atherogenesis and established plaques. Circ Res 2007;100:884-893.

24 Tabas I: Macrophage death and defective inflammation resolution in atherosclerosis. Nat Rev Immunol 2010;10:36-46.

25 Swirski FK, Weissleder R, Pittet MJ: Heterogeneous in vivo behavior of monocyte subsets in atherosclerosis. Arterioscler Thromb Vasc Biol 2009;29:1424-1432.

26 Leon ML, Zuckerman SH: Gamma interferon: a central mediator in atherosclerosis. Inflamm Res 2005;54:395-411.

27 Canault M, Peiretti F, Poggi M, Mueller C, Kopp F, Bonardo B, Bastelica D, Nicolay A, Alessi MC, Nalbone G: Progression of atherosclerosis in ApoE-deficient mice that express distinct molecular forms of TNF-alpha. J Pathol 2008;214:574-583. 